\title{
Surface Finish Comparison of Dry and Coolant Fluid High-Speed Milling of JIS SDK61 Mould Steel
}

\author{
The-Hung Le \\ Faculty of Mechanical Engineering \\ Hanoi Vocational College of High Technology \\ Hanoi, Vietnam \\ hunglt@hht.edu.vn
}

\author{
Van-Bong Pham \\ Faculty of Mechanical Engineering \\ Hanoi University of Industry \\ Hanoi, Vietnam \\ phamvanbong@haui.edu.vn
}

\author{
Dung Hoang Tien \\ Faculty of Mechanical Engineering \\ Hanoi University of Industry \\ Hanoi, Vietnam \\ tiendung@haui.edu.vn
}

\begin{abstract}
This paper investigates the influence of dry high-speed milling on the surface quality of JIS SKD61 hard steel, compared to the conventional coolant fluid method. This research was conducted in a Super MC 500 high-speed CNC milling machine with a Hitachi coated carbide $20 \mathrm{~mm}$ in diameter. High-speed cutting parameters such as cutting speed $V$, cutting depth $t$, and spindle speed $S$ were considered as variants. The experiment was designed based on Taguchi's L9. Surface quality, including $R a$ and $R q$, was measured using the Mitutoyo Surftest SV-210. A mathematical regression model was found for the average values of surface roughness through regression analysis for dry and coolant fluid conditions. The chosen high-speed milling parameters and the respective $R a$ and $R q$ values were obtained by ANOVA. The grey relation scores for wet and dry milling surface quality for cut depth, feed rate, and cutting speed were $0.7527,0.7869,0.6302$, and $0.8167,0.7199,0.6040$, respectively. The results showed that the feed rate had the greatest influence on the surface quality during the high-speed coolant milling of hardened steel, while the depth of the cut had the greatest influence on the surface quality during the high-speed dry milling process.
\end{abstract}

Keywords-SKD61; FGRA; surface roughness; high-speed milling

\section{INTRODUCTION}

JIS SKD61 (or AISI H13) alloy steel is a hot work mold steel, popular for its remarkable toughness, sufficient resistance to high-temperature fatigue, and high rigidity. In general, the manufacturing processes of extrusion die sets, hot forging, and casting dies include roughing, heat treatment, and machine finishing. This process is costly and time-consuming. The increasing pressure in the global economy forces the manufacturers to increase machining productivity while maintaining or improving product quality. The improvement of the cutting productivity and quality of high-speed cutting processes have attracted the attention of many companies and researchers in recent decades.

The coolant fluid is essential when milling hardened steel or other difficult-to-machine materials, especially when machining at high speeds. The main effect of a coolant in milling is to reduce temperature and friction, prolong the life of the cutting tool, and improve the machining efficiency and surface quality [1-3]. Moreover, a coolant also has anticorrosion and cleaning effects $[4,5]$. Nowadays, with the continuous development of precision and ultra-precision machining, machined surface integrity is more important than cutting efficiency and tool life, especially for important components such as mold parts working in harsh environments. However, the effect of the coolant fluid on machined surface quality and its performance in the high-speed machining of hardened steels has not been given attention and compared with dry milling under the same machining conditions.

The cost of the coolant fluid can increase the total production cost by up to $15 \%$ [6]. Dry, near-dry, and MQL machining processes are viable alternatives to reduce this cost. Dry machining is now considered an excellent solution to minimize the negative impacts on human health and the environment. Therefore, dry or near-dry machining has attracted considerable interest among manufacturers and researchers [7]. Dry milling can offer significant advantages such as reducing pollutants in the air, water, or the earth, having less harmful effects on human health [20], and a significant cost reduction as there is no need to invest in cooling equipment, maintenance, operation, and handling coolant after machining [8, 9]. Dry milling processes can be applied to a wide range of materials, such as cast iron, carbon steel, alloy steel, and difficult-to-machine steels [10, 11]. However, in dry milling conditions, due to the large friction between the tool and the workpiece, the cutting temperature increases and causes increased wear of the cutting tool. Build of edge also appears more frequently [9], adversely affecting 
the quality of the machined surface. Although the further improvement of surface quality and the reduction of tool wear during dry milling has attracted the interest of many researchers, most of them focused on measures to offset the positive effects of lubricants through the optimal selection of cutting parameters, changing the geometry of the cutting tool, choosing the right tool material, improving the machine, etc. However, these studies have not mentioned or compared the main factors that affect surface quality between the wet and dry milling process.

This study examined the factors influencing the dry and wet high-speed milling of hardened steel on surface quality under the same machining conditions. Fuzzy Grey Relationship Analysis (FGRA) was applied to determine the influence of each factor on surface quality in the two different milling environments. Based on the experimental results obtained by the Taguchi L9 method, the FGRA processes were used to evaluate the main factors affecting surface quality. The dry and wet milling comparison provides excellent reference values to be applied to the machining processes and further improve the surface quality of high-speed milling of hardened steel.

\section{EXPERIMENTAL SETUP}

\section{A. The Workpiece}

The SKD61 hard steel, used as the workpiece specimen, was prepared in square blocks of $70 \times 40 \times 15 \mathrm{~mm}$ dimensions. The chemical composition and mechanical properties of JIS SKD61 mold steel are demonstrated in Tables I and II.

TABLE I. CHEMICAL COMPOSITION OF JIS SKD61 HARD STEEL

\begin{tabular}{|c|c|c|c|c|c|c|c|c|c|}
\hline $\mathbf{C}$ & $\mathbf{S i}$ & $\mathbf{M n}$ & $\mathbf{P}$ & $\mathbf{S}$ & $\mathbf{C r}$ & $\mathbf{M o}$ & $\mathbf{N i}$ & $\mathbf{C u}$ & $\mathbf{V}$ \\
\hline 0.349 & 0.582 & 0.720 & 0.001 & 0.001 & 5.59 & 1.18 & 0.062 & 0.036 & 0.573 \\
\hline
\end{tabular}

TABLE II. MECHANICAL PROPERTIES OF JIS SKD61 HARD STEEL

\begin{tabular}{|l|c|c|}
\hline \multicolumn{1}{|c|}{ Properties } & Metric & Imperial (Psi) \\
\hline Tensile strength at $20^{\circ} \mathrm{C}$ & $1.200 \div 1.590 \mathrm{MPa}$ & $174.000 \div 231.000$ \\
\hline Tensile strength, yield at $20^{\circ} \mathrm{C}$ & $1.000 \div 1.380 \mathrm{MPa}$ & $145.000 \div 200.000$ \\
\hline Reduction of area at $20^{\circ} \mathrm{C}$ & $50 \%$ & $50 \%$ \\
\hline Modulus of elasticity at $20^{\circ} \mathrm{C}$ & $215(\mathrm{Gpa})$ & 31.200 \\
\hline Poisson's ratio & $0.27 \div 0.30$ & $0.27-0.30$ \\
\hline
\end{tabular}

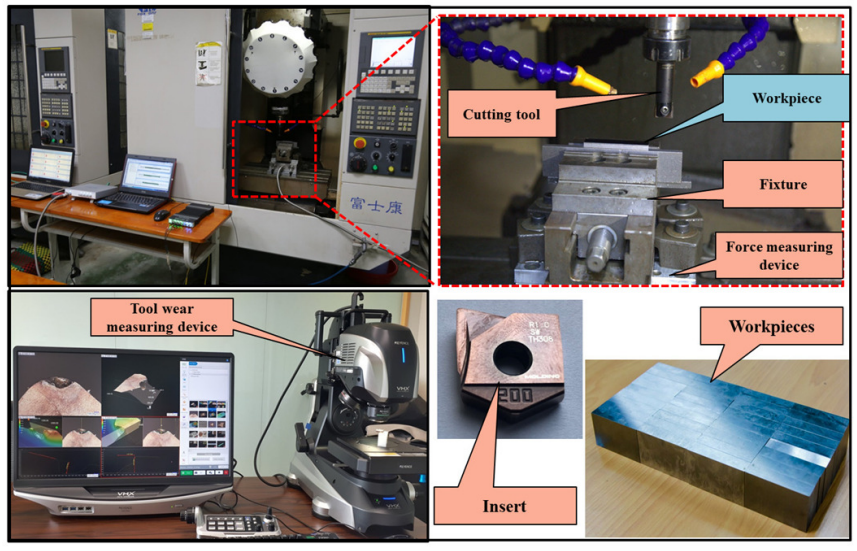

Fig. 1. Super MC 500 high-speed CNC milling machine.

\section{B. Machine and Cutting Tool}

An MC50 high-speed machine, made by Foxconn Corporation and a Hitachi cutting tool with coated inserts were used for the experiment process (Figure 1).

\section{Measurement Equipment}

The surface roughness value for all experiments was determined as the average of three measurements at separate locations in the workpiece specimens using a Mitutoyo Surftest SV-210. These average values are shown in Table III.

\section{APPLYING GREY FUZZY RELATIONSHIP ANALYSIS}

GRA is an effective statistical method to measure the approximation between objects using the grey relational level. The model has been successfully applied in many different fields [12-14]. The level of information in a GRA assists decision-making in difficult situations $[15,16]$. An improved version of this method is the Fuzzy Grey Relationship Analysis (FGRA). This is an approach based on a fuzzy system developed on coefficients and grey relation levels. This model considers all the different criteria, including their importance and the uncertainty about the weights. In this work, FGRA was used to evaluate the effects of various factors from the cutting mode parameters on the machined surface quality in both dry and wet milling environments. The steps of the algorithm are described as follows:

- Step 1: When applying FGRA to determine the factors affecting surface quality in wet and dry milling, the reference matrix $Y$ is established based on the surface roughness parameters obtained. $\quad Y(1), \quad Y(2), \ldots, \quad Y(n)$ correspond to the surface roughness values obtained by the experiments $1,2, \ldots, n$. The reference matrix with the surface quality in high-speed milling is described by:

$$
Y=[Y(1) Y(2) \ldots Y(n)]
$$

The factors investigated in the high-speed milling process include inputs such as cutting speed, feed, wet milling, dry milling, etc. in the experiments. If the number of the investigated factors is $m$ and the number of experiments is $n$, the comparison matrix is:

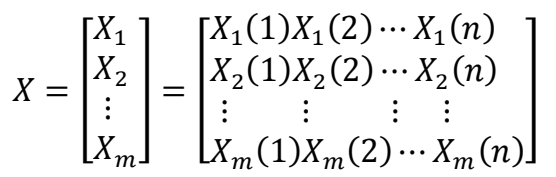

- Step 2: Nondimensionalize original sequences. As the investigated factors (surface roughness) and the reference variables (depth of cut $t$, feed rate $S$, cutting speed $V$ ) have different dimensions, they must be nondimensionalized by [17]:

$$
X_{i}(k)^{\prime}=\frac{X_{i}(k)-\operatorname{Min}\left[X_{i}(k)\right]}{\operatorname{Max}\left[X_{i}(k)\right]-\operatorname{Min}\left[X_{i}(k)\right]}
$$

- Step 3: Calculate the cosine value of the fuzzy membership. In this study, the included-angle cosine method was adopted, which is not affected by the linear proportional relationship of the data. The similarity of the two factors 
was determined by the included-angle cosine of the two factors, which was calculated by [18]:

$$
R_{1}=\frac{\sum_{k=1}^{n} Y(k) X(k)}{\sqrt{\sum_{k=1}^{n} Y(k)^{2}} \sqrt{\sum_{k=1}^{n} X(k)^{2}}}
$$

- Step 4: The grey level relationship was calculated by [18]:

$$
\xi_{i}=\frac{l \cdot \Delta_{\max }+\Delta_{\min }}{l . \Delta_{\max }+\Delta(k)}
$$

This variant must be suitable for working conditions and resist any noise signal, as the values of dispersion coefficients may not accurately reflect the relationship between the investigated variants. The dispersion coefficient was calculated by [14]:

$$
\Delta=\frac{1}{n \cdot m} \sum_{j=1}^{m} \sum_{k=1}^{n}\left|Y_{t}(k)-X_{t j}(k)\right|
$$

where $\Delta$ is the absolute error's mean. As $C=\frac{\Delta}{\Delta_{\max }}$, the resolution factor was obtained as:

$$
L \in \begin{cases}{[C ; 1,5 \times C] ;} & C<\frac{1}{3} \\ (1,5 \times C ; 2 C] ; & C \geq \frac{1}{3}\end{cases}
$$

If $C<\frac{1}{3}$, then $L=1.25 C$. If $C \geq \frac{1}{3}$ then $L=1.75 C$.

- Step 5: The Euclidean distance was used to determine the difference between the comparison and reference matrices and increase the accuracy of the estimation processes. Therefore, the weight vector of the different elements in the reference matrix was defined by:

$$
W=(W 1, W 2, \ldots, W j), j=1,2, \ldots, n
$$

The grey Euclidean R2 levels were calculated using [17]:

$$
R_{2}=1-2 \sqrt{\sum_{k=1}^{n}\left[W\left\{1-\xi_{i}(k)\right\}\right]^{2}}
$$

- Step 6: Determine the fuzzy grey points. According to the fuzzy association coefficient, the grey relationship's level and grey relationship with the fuzzy correlation coefficient of the research variants were calculated by:

$$
R=\sqrt{\frac{R_{1}^{2}+R_{2}^{2}}{2}}
$$

- Step 7: Ranking. Based on the magnitude of the grey relational grade, the impact of the investigated factors was ranked.

\section{EXPERIMENTAL PROCEDURE}

The experiment was designed based on the Taguchi orthogonal array [19] to reduce the number of experiments. Two responses, $R_{a}$ and $R_{q}$, were analyzed simultaneously in both dry and coolant fluid environments. Cutting speed $V$, spindle speed $S$, and depth of cut $t$ were chosen. Table III shows the high-speed milling parameters and results.

\section{RESULTS AND DISCUSSION}

Figures 2 and 3 depict a quality comparison of the workpiece surface in wet and dry milling, according to $R_{a}$ and
$R_{q}$, respectively. The results show that the surface quality in dry is lower than in coolant fluid milling with the same cutting parameters.

TABLE III. EXPERIMENTAL RESULTS

\begin{tabular}{|c|c|c|c|c|c|c|c|}
\hline \multirow{2}{*}{ No } & \multicolumn{3}{|c|}{$\begin{array}{c}\text { Variant } \\
\text { code }\end{array}$} & \multicolumn{2}{c|}{$\begin{array}{c}\text { Surface quality in flood } \\
\text { cooling condition }\end{array}$} & \multicolumn{2}{c|}{$\begin{array}{c}\text { Surface quality in dry } \\
\text { condition }\end{array}$} \\
\cline { 2 - 8 } & $\boldsymbol{t}$ & $\boldsymbol{S}$ & $\boldsymbol{V}$ & $\boldsymbol{R}_{\boldsymbol{a}}(\boldsymbol{\mu m})$ & $\boldsymbol{R}_{\boldsymbol{q}}(\boldsymbol{\mu} \mathbf{m})$ & $\boldsymbol{R}_{\boldsymbol{a}}(\boldsymbol{\mu m})$ & $\boldsymbol{R}_{\boldsymbol{q}}(\boldsymbol{\mu} \mathbf{m})$ \\
\hline 1 & 1 & 1 & 1 & 0.382 & 0.464 & 0.543 & 0.615 \\
\hline 2 & 1 & 2 & 2 & 0.714 & 0.836 & 1.314 & 1.525 \\
\hline 3 & 1 & 3 & 3 & 1.492 & 1.712 & 1.829 & 2.290 \\
\hline 4 & 2 & 1 & 2 & 0.827 & 1.011 & 0.978 & 1.117 \\
\hline 5 & 2 & 2 & 3 & 0.405 & 0.487 & 0.536 & 0.622 \\
\hline 6 & 2 & 3 & 1 & 0.56 & 0.666 & 1.317 & 1.557 \\
\hline 7 & 3 & 1 & 3 & 0.848 & 1.046 & 1.000 & 1.204 \\
\hline 8 & 3 & 2 & 1 & 0.521 & 0.613 & 0.521 & 0.616 \\
\hline 9 & 3 & 3 & 2 & 1.010 & 1.215 & 1.301 & 1.588 \\
\hline
\end{tabular}

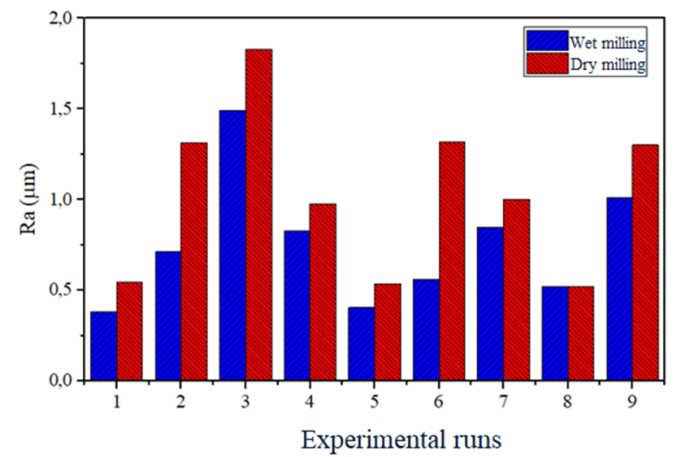

Fig. 2. $\quad R_{a}$ surface roughness comparison in wet and dry milling.

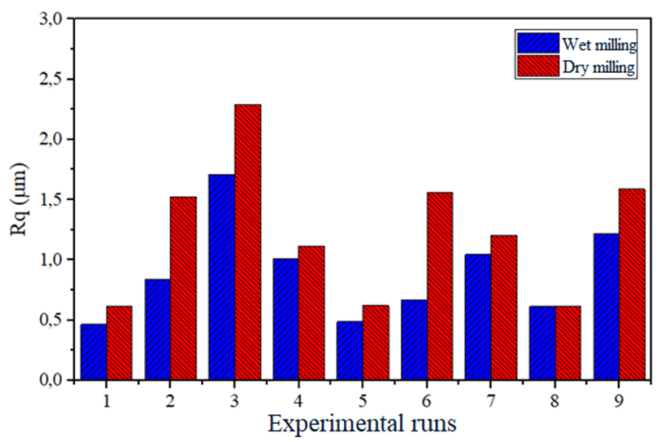

Fig. 3. $R_{q}$ surface roughness comparison in wet and dry milling.

The ANOVA results of the surface quality in wet milling conditions are shown in Figure 4. The results show that the smallest $\mathrm{S} / \mathrm{N}$ ratios were in level 3 for all variables. Feed rate $S$ had the smallest $\mathrm{S} / \mathrm{N}$ ratio $(0.31)$, followed by cutting speed (0.99) and depth of cut (2.15). The ANOVA results in dry milling conditions are shown in Figure 5. The results show that feed rate $S$ and cutting speed $V$ had the smallest $\mathrm{S} / \mathrm{N}$ ratios in level 3 (-3.36, -2.92, respectively). Depth of cut $t$ had its smallest $\mathrm{S} / \mathrm{N}$ ratio in level $1(-0.78)$. Therefore, there is a significant difference in the ANOVA results between the wet and dry milling processes. The FGRA was applied to determine the main factors affecting the surface quality through the following steps: 
- Step 1: The surface quality of different machining conditions had the $Y(x)$ and $Z(y)$ reference arrays for wet and dry milling, respectively. The depth of cut, feed rate, and cutting speed were $Y 1(x), Y 2(x), Y 3(x)$, and $Z 1(x)$,

$$
\begin{aligned}
& {\left[\begin{array}{l}
Y_{1}(x) \\
Y_{2}(x) \\
Y_{3}(x) \\
Y(x)
\end{array}\right]=\left[\begin{array}{ccccccccc}
1 & 1 & 1 & 2 & 2 & 2 & 3 & 3 & 3 \\
1 & 2 & 3 & 1 & 2 & 3 & 1 & 2 & 3 \\
1 & 2 & 3 & 2 & 3 & 1 & 3 & 1 & 2 \\
0.382 & 0.714 & 1.492 & 0.827 & 0.405 & 0.56 & 0.848 & 0.521 & 1.010
\end{array}\right]} \\
& {\left[\begin{array}{l}
Z_{1}(x) \\
Z_{2}(x) \\
Z_{3}(x) \\
Z(x)
\end{array}\right]=\left[\begin{array}{ccccccccc}
1 & 1 & 1 & 2 & 2 & 2 & 3 & 3 & 3 \\
1 & 2 & 3 & 1 & 2 & 3 & 1 & 2 & 3 \\
1 & 2 & 3 & 2 & 3 & 1 & 3 & 1 & 2 \\
0.543 & 1.314 & 1.829 & 0.978 & 0.536 & 1.317 & 1.000 & 0.521 & 1.301
\end{array}\right]}
\end{aligned}
$$

$Z 2(x), Z 3(x)$ for conventional and dry milling, respectively. The reference and the comparison matrixes are shown in (11) and (12).

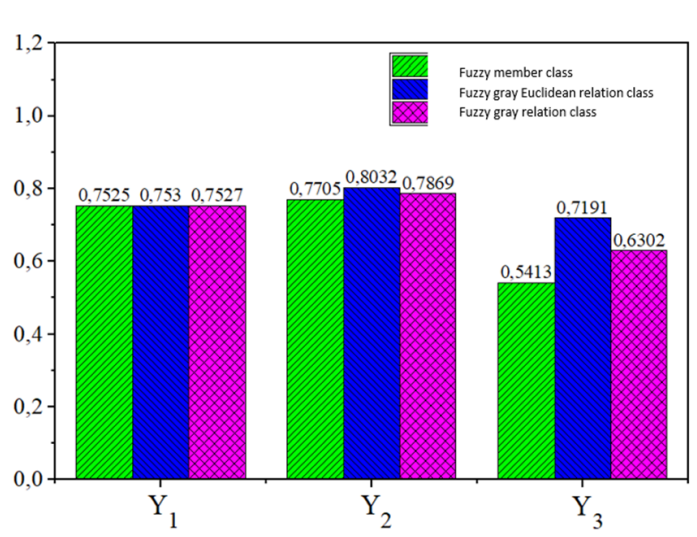

Fig. 6. Grayscale analysis to surface quality in wet milling.

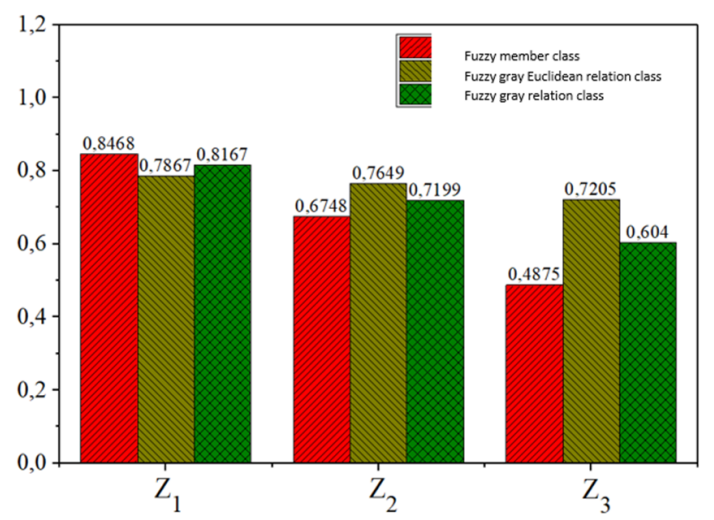

Fig. 7. Grayscale analysis to surface quality in dry milling

- Step 4: The fuzzy grey relationship scores of the input variants were obtained by (12) and are illustrated in Figures 6 and 7. The results showed a comprehensive way to evaluate the impact of experimental variants on the surface quality in both convenient and dry milling conditions. Therefore, the matt grey related scores for wet and dry milling surface quality of the three factors depth of cut $t$, feed rate $S$, and cutting speed $v$ were $0.7527,0.7869$, 0.6302 , and $0.8167,0.7199,0.6040$, respectively.

Hence, the influence of feed rate on the surface quality in the high-speed machining of a difficult-to-cut material in wet milling is the most. By contrast, the depth of cut has the most 
significant influence on the surface roughness in dry machining, while the cutting speed has an almost negligible effect on the surface quality in both dry and wet milling methods.

\section{CONCLUSION}

This study investigated the high-speed cutting parameters optimization of milling processes in dry and coolant fluid conditions to ensure a satisfactory surface quality. FGRA was obtained to analyze the relation among the surface roughness parameters $R_{a}, R_{q}$, and the cutting parameters cutting speed $v$, spindle speed $S$, and depth of cut $t$. ANOVA was used to determine the model's adequacy and factor significance. The main results can be summarized as:

- The surface quality in high-speed milling of mold steel JIS SKD61 in dry conditions is lower than in coolant fluid conditions with the same cutting parameters.

- The effects of different cutting parameters on the surface roughness in dry and coolant fluid environments differ. Cutting speed $v$ had the smallest $\mathrm{S} / \mathrm{N}$ value at 0.31 and 0.21 , respectively. By contrast, the $\mathrm{S} / \mathrm{N}$ value of the depth of cut $t$ was highest, at 2.51 and -0.78 , respectively, followed by the $\mathrm{S} / \mathrm{N}$ of spindle speed $S$.

- The FGRA confirmed that the influence of spindle speed was the most in the coolant fluid high-speed milling of hardened steel. By contrast, the effect of depth of cut on the surface roughness in the dry machining was the most significant. At the same time, both dry and wet conditions showed that the influence of cutting speed was insignificant.

\section{ACKNOWLEDGMENT}

The authors highly appreciate Hanoi University of Industry (https://haui.edu.vn) for supporting the research process.

\section{NOMENCLATURE}

$\begin{array}{ll}\mathrm{X} & \text { Comparison matrix } \\ \mathrm{Y} & \text { Reference matrix } \\ l & \text { Resolution coefficient, } l \in[0,1] \\ \Delta_{\min } & \text { Minimum absolute difference, } \Delta_{\min }=\min \left|Y(k)-X_{i}(k)\right| \\ \Delta_{\max } & \text { Maximum absolute difference, } \Delta_{\max }=\max \left|Y(k)-X_{i}(k)\right| \\ \Delta(k) & \text { Absolute difference, } \Delta(k)=\left|Y(k)-X_{i}(k)\right| \\ \xi_{i} & \text { Relational coefficient } \\ R & \text { Fuzzy grey relational grade } \\ R_{1} & \text { Fuzzy membership grade } \\ R_{2} & \text { Euclidean grey relational grade }\end{array}$

\section{REFERENCES}

[1] B. T. Daymond, N. Binot, M. L. Schmidt, S. Preston, R. Collins, and A. Shepherd, "Development of Custom 465® Corrosion-Resisting Steel for Landing Gear Applications," Journal of Materials Engineering and Performance, vol. 25, no. 4, pp. 1539-1553, Apr. 2016, https://doi.org/ 10.1007/s11665-015-1830-5.

[2] K. J, P. V, K. V, and G. Priyadharshini B, "Multi response optimization of process parameters using grey relational analysis for milling of hardened Custom 465 steel," Procedia Manufacturing, vol. 30, pp. 451458, Jan. 2019, https://doi.org/10.1016/j.promfg.2019.02.064.

[3] D. H. Tien, Q. T. Duc, T. N. Van, N.-T. Nguyen, T. Do Duc, and T. N. Duy, "Online monitoring and multi-objective optimisation of technological parameters in high-speed milling process," The International Journal of Advanced Manufacturing Technology, vol. 112, no. 9, pp. 2461-2483, Feb. 2021, https://doi.org/10.1007/s00170-02006444-X.

[4] C. Wang, Y. Xie, L. Zheng, Z. Qin, D. Tang, and Y. Song, "Research on the Chip Formation Mechanism during the high-speed milling of hardened steel," International Journal of Machine Tools and Manufacture, vol. 79, pp. 31-48, Apr. 2014, https://doi.org/10.1016/ j.ijmachtools.2014.01.002.

[5] T. D. Hoang, N.-T. Nguyen, D. Q. Tran, and V. T. Nguyen, "Cutting Forces and Surface Roughness in Face-Milling of SKD61 Hard Steel.," Strojniski Vestnik - Journal of Mechanical Engineering, vol. 65, no. 6, pp. 375-386, Jun. 2019.

[6] S. Kalpakjian and S. Schmid, Manufacturing Engineering \& Technology, 7th edition. Upper Saddle River, NJ, USA: Pearson, 2013.

[7] J. Haider and M. S. J. Hashmi, "Health and Environmental Impacts in Metal Machining Processes," in Comprehensive Materials Processing, S. Hashmi, G. F. Batalha, C. J. Van Tyne, and B. Yilbas, Eds. Oxford, UK: Elsevier, 2014, pp. 7-33.

[8] A. W. El-Morsy, "Wear Analysis of a Ti-5Al-3V-2.5Fe Alloy Using a Factorial Design Approach and Fractal Geometry," Engineering, Technology \& Applied Science Research, vol. 8, no. 1, pp. 2379-2384, Feb. 2018, https://doi.org/10.48084/etasr.1743.

[9] L. Lu et al., "Microstructure and cutting performance of CrTiAlN coating for high-speed dry milling," Transactions of Nonferrous Metals Society of China, vol. 24, no. 6, pp. 1800-1806, Jun. 2014, https://doi.org/10.1016/S1003-6326(14)63256-8.

[10] T.-T. Nguyen, "Prediction and optimization of machining energy, surface roughness, and production rate in SKD61 milling," Measurement, vol. 136, pp. 525-544, Mar. 2019, https://doi.org/ 10.1016/j.measurement.2019.01.009.

[11] E. Vazquez, J. Gomar, J. Ciurana, and C. A. Rodríguez, "Analyzing effects of cooling and lubrication conditions in micromilling of Ti6Al4V," Journal of Cleaner Production, vol. 87, pp. 906-913, Jan. 2015, https://doi.org/10.1016/j.jclepro.2014.10.016.

[12] S. Singh, "Optimization of machining characteristics in electric discharge machining of $6061 \mathrm{Al} / \mathrm{Al} 2 \mathrm{O} 3 \mathrm{p} / 20 \mathrm{P}$ composites by grey relational analysis," The International Journal of Advanced Manufacturing Technology, vol. 63, no. 9, pp. 1191-1202, Dec. 2012, https://doi.org/10.1007/s00170-012-3984-8.

[13] Z. Li, W. Ding, C. Liu, and H. Su, "Prediction of grinding temperature of PTMCs based on the varied coefficients of friction in conventionalspeed and high-speed surface grinding," The International Journal of Advanced Manufacturing Technology, vol. 90, no. 5, pp. 2335-2344, May 2017, https://doi.org/10.1007/s00170-016-9578-0.

[14] D. Nguyen, J. Wu, N. M. Quang, L. A. Duc, and P. X. Son, "Applying fuzzy grey relationship analysis and Taguchi method in polishing surfaces of magnetic materials by using magnetorheological fluid," The International Journal of Advanced Manufacturing Technology, vol. 112, no. 5, pp. 1675-1689, Jan. 2021, https://doi.org/10.1007/s00170-02006567-1.

[15] R. S. Pawade and S. S. Joshi, "Multi-objective optimization of surface roughness and cutting forces in high-speed turning of Inconel 718 using Taguchi grey relational analysis (TGRA)," The International Journal of Advanced Manufacturing Technology, vol. 56, no. 1, pp. 47-62, Sep. 2011, https://doi.org/10.1007/s00170-011-3183-z.

[16] H. Zhou, W.-F. Ding, Z. Li, and H.-H. Su, "Predicting the grinding force of titanium matrix composites using the genetic algorithm optimizing back-propagation neural network model," Proceedings of the Institution of Mechanical Engineers, Part B: Journal of Engineering Manufacture, vol. 233, no. 4, pp. 1157-1167, Mar. 2019, https://doi.org/10.1177/ 0954405418780166 .

[17] A. Kadier, P. Abdeshahian, Y. Simayi, M. Ismail, A. A. Hamid, and M. S. Kalil, "Grey relational analysis for comparative assessment of different cathode materials in microbial electrolysis cells," Energy, vol. 90, pp. 1556-1562, Oct. 2015, https://doi.org/10.1016/j.energy.2015.06. 108.

[18] N. Duy Trinh, N. Nhat Tan, N. M. Quang, P. Thi Thieu Thoa, and L. A. Duc, "Application of magnetic liquid slurries and fuzzy grey analysis in polishing nickel-phosphorus coated SKD11 steel," Particulate Science 
and Technology, pp. 1-14, Jul. 2021, https://doi.org/10.1080/ 02726351.2021 .1948471

[19] V. C. Nguyen, T. D. Nguyen, and D. H. Tien, "Cutting Parameter Optimization in Finishing Milling of Ti-6Al-4V Titanium Alloy under MQL Condition using TOPSIS and ANOVA Analysis," Engineering, Technology \& Applied Science Research, vol. 11, no. 1, pp. 6775-6780, Feb. 2021, https://doi.org/10.48084/etasr.4015.

[20] F. Siddiqui, M. A. Akhund, A. H. Memon, A. R. Khoso, and H. U. Imad, "Health and Safety Issues of Industry Workmen," Engineering, Technology \& Applied Science Research, vol. 8, no. 4, pp. 3184-3188, Aug. 2018, https://doi.org/10.48084/etasr.2138.

\section{AUTHORS' PROFILE}

The-Hung Le is a lecturer at Hanoi Vocational College of High Technology. He is a $\mathrm{PhD}$ candidate in the Faculty of Mechanical Engineering at Hanoi University of Industry. His research work focuses on the multiple optimizations of high-speed machining process of hardcutting alloy steel.

Van-Bong Pham is an associated professor in the Manufacturing Department, Faculty of Mechanical Engineering, Hanoi University of Industry. His research work focuses on the multi-optimization of the cutting processes.

Dung Hoang Tien is an associated professor in the Mechanical Technology Department, Faculty of Mechanical Engineering, Hanoi University of Industry. His research work focuses on dynamic machining, modeling and optimization, adaptive machining, AM/3D printing technology, and micro-machining. 